Asian J. Med. Biol. Res. 2020, 6 (4), 674-682; doi: 10.3329/ajmbr.v6i4.51233

\author{
Asian Journal of \\ Medical and Biological Research \\ ISSN 2411-4472 (Print) 2412-5571 (Online) \\ www.ebupress.com/journal/ajmbr
}

\title{
Article
}

\section{Dietary behaviour of pregnant women with anaemia in Bangladesh}

\author{
Salma Khatun ${ }^{1 *}$, Ashees Kumar Saha ${ }^{2}$, Seungmi Park ${ }^{3}$, Aysha Siddika ${ }^{4}$, Papia Sultana ${ }^{5}$ and Fahmida Khatun ${ }^{6}$ \\ ${ }^{1}$ National Institute of Cardio Vascular Diseases (NICVD), Dhaka, Bangladesh \\ ${ }^{2}$ Nursing Officer, Upazila Health Complex, Bagha, Rajshahi, Bangladesh \\ ${ }^{3}$ Department of Nursing, Chungbuk National University, South Korea \\ ${ }^{4}$ Dhaka Medical College Hospital, Dhaka, Bangladesh \\ ${ }^{5}$ National Institute of Ear, Nose and Throat (ENT), Tejgoan, Dhaka, Bangladesh \\ ${ }^{6}$ Faculty of Women's Health and Midwifery, National Institute of Advance Nursing Education and Research \\ (NIANER), Mugda, Dhaka, Bangladesh
}

*Corresponding author: Salma Khatun, Senior Staff Nurse, National Institute of Cardio Vascular Diseases (NICVD), Dhaka, Bangladesh. Phone: +8801911144444; E-mail: salmamonebd@gmail.com

Received: 10 November 2020/Accepted: 21 December 2020/ Published: 31 December 2020

\begin{abstract}
In pregnancy a healthy dietary behavior is beneficial for the expecting mother and her fetus. Anemia is one of the most common nutritional deficiency disorders that can be prevented through promoting dietary behavior. The aim of this study is to examine the dietary behavior of pregnant woman with anemia in Bangladesh. A descriptive cross-sectional study design was applied. By using G* Power, 135 pregnant women were purposively recruited from $\mathrm{MMCH}$, Dhaka. Data was analyzed by using descriptive statistics and inferential statistics, independent t-test and one way ANOVA. Findings showed the mean age of the participants was $25(\mathrm{SD}=4.96)$ years. Multi gravida was $55.6 \%$ and $68.1 \%$ reported their medium healthy condition. The average dietary behavior reported $56.03(\mathrm{SD}=6.15)$ and $67.4 \%$ participants' hemoglobin concentration were within 10-10.9 g/dl. In bivariate analysis, finding showed that anemia has significantly related with age $(\mathrm{F}=$ $12.88, p<001)$, level of education $(\mathrm{F}=2.92, p=.036)$, income $(\mathrm{r}=0.19, p=.027)$, gravida $(\mathrm{F}=5.63, p=.004)$ health condition $(\mathrm{F}=10.89, p<001)$. The result of dietary behaviors showed that anemia has positively correlated $(\mathrm{r}=0.21, p=.017)$ with dietary behavior. Dietary behavior is related with some factors, age, low level education, grand multi and primiparous, poor health condition found less hemoglobin concentration indicate as less dietary intake. Monthly income and dietary behavior impact in increasing Hemoglobin concentration. In this regards, maternal nurses might play a vital role for providing nursing intervention to improve pregnant women's dietary behavior.
\end{abstract}

Keywords: dietary behaviour; pregnant women; anaemia; health status; out-patient department; health related characteristics

\section{Introduction}

Dietary behavior is the eating practice for health benefits, especially during pregnancy associated with nutrition deficiency diseases. Anemia is one of the most common nutritional deficiency diseases observed globally, including Bangladesh. It is recognized that the nutritional disorder, affecting more than two billion people in both developed and developing countries (Chowdhury et al., 2015).

In Bangladesh, surveys over the past 10 years have estimated the prevalence of anemia among women of reproductive age to range from $23 \%$ to $95 \%$, depending on age, pregnancy status, and urban versus rural residency (Dayal and Dayal, 2014). Bangladesh Demographic and Health survey (2011) showed that over past 16 years the prevalence of anemia in pregnant women was $48.10 \%$ compared to the broader south-east Asian prevalence of $85 \%$ (Imdad and Bhutta, 2012). The World Health Organization (WHO) reported that the prevalence of anemia among pregnant woman in developed countries is 14\% (Dayal and Dayal, 2014) and 42\% 
globally; such pervasiveness across all economic circumstances pose a major threat to maternal health (Ejeta et al., 2014). Research showed that more than 50\% (Haider, 2013) to 90\% (Campigotto et al., 2015) of anemia during pregnancy occurring due to iron deficiency, (Christian, et al 1998) is assumed improper dietary behavior. Pregnant women are vulnerable to deficiencies in iron, folate, cobalamin and vitamin A, a lack of which can cause anemia (Bondevik et al., 2000). The risk factors for anaemia, particularly during pregnancy are multiple and complex (Hoque et al., 2009). The most common one is iron deficiency and deficiencies of other micronutrients such as vitamin A, folic acid, zinc, copper, and other vitamins and minerals. Other risk factors include frequent pregnancies, severe infections such as malaria, HIV/AIDS, Hookworm, other Intestinal helminthes infections, poor economic status (Kedir et al., 2013), the season, food habits, gestational age, parity, early age of marriage and geographic location (Aikawa et al., 2006).

Pregnant women are often the main victims of undesirable dietary practices, which are responsible for malnutrition. Despite the fact that the nutrient and energy requirements of pregnant women are higher than normal people, pregnant women in Bangladesh specifically avoid nutrient-rich meals such as fruits, eggs, milk, and certain types of fish due to flowed superstition (Islam and Cliah, 2005).

Anemia in pregnancy is commonly considered a risk factor for the poor pregnancy outcome and can result in complications that threaten the life of both mother and fetus. For the mother, this condition can reduce the individual's work performance, reduce resistance to infection, and increase the risk of mortality during pregnancy. For the fetus, anemia can impair its mental and psychomotor development, increase the probability of low birth weight and increase the risk of mortality at birth (Campigotto et al., 2015), dietary inadequacy increased probability of low birth weight and cause increased maternal and child morbidity and mortality (Zhang et al., 2010).

Anemia in pregnant women is defined as a hemoglobin concentration of less than $11 \mathrm{~g} / \mathrm{dl}$ in the blood. Anemia during pregnancy is considered severe when hemoglobin concentration is less than $7.0 \mathrm{~g} / \mathrm{dl}$, moderate when hemoglobin falls between 7.0 and $9.9 \mathrm{~g} / \mathrm{dl}$, and mild when hemoglobin concentration is from 10.0 to $11 \mathrm{~g} / \mathrm{dl}$ (Bekele et al., 2016). It is one of the most prevalent nutritional deficiency problems affecting pregnant woman. (Chowdhury et al., 2015)

In adequate intake of energy and nutrients affect not only the pregnant woman but also impaired fetal growth and develop optimally (Northstone et al., 2008). While anemia is clearly a deadly condition affecting millions of pregnant women in Bangladesh. It is a preventable condition with the appropriate care. In this regards maternal nurse may play a role to promote dietary behavior of pregnant women for wellbeing of them and their newborn as well. Therefore, study is conducted to examine the dietary behavior of mothers with pregnancy. These study findings might be helped to prevent the spread of anemia and pregnancy associated morbidity and mortality in Bangladesh. The aim of this study is to examine the dietary behavior of pregnant women with anemia in Bangladesh with specific objectives of to describe the health related characteristics of pregnant women with anaemia, to explore the dietary behavior of pregnant woman with anaemia in Bangladesh, to examine the relationship between demographic characteristics and anaemia of pregnant woman, to examine the relationship between health status, dietary behaviour and anemia in pregnant women.

\section{Materials and Methods}

\subsection{Ethical consideration}

After obtaining ethical permission from concerned authorities and participants, data were collected. Participation was voluntary and anonymity was guaranteed. Based on returning and completing the questionnaire by the participants were considered as eligible subjects who signed written informed consent form and completed questionnaire in this study. Subjects could be withdrawn at any time without any reason.

\subsection{Study design}

A descriptive cross-sectional study design was used to examine the dietary behavior of pregnant women with anemia in Bangladesh.

\subsection{Study population}

Pregnant woman came in Gynae Out-Patient Department (GOPD) to receive maternal services.

\subsection{Study periods and others}

Total study period was 1 (one) year from 1st July, 2017 to 30 June, 2018. 


\subsubsection{Study Place}

The study was conducted in MMCH at Gynae Out-Patient Department.

\subsubsection{Sampling technique}

Purposive sampling technique was used. The sample size of this study was 120 pregnant women estimated by using G- power analysis. In the calculation, the accepted minimum level of significance $(\alpha) .05$, power $(1-\beta) .80$ and the effect size .30 estimated 120 sample size. Due to potential risk of dropout or missing data, researcher included $20 \%$ attrition rate, therefore total sample size was 135 .

\subsubsection{Inclusion criteria}

The inclusion criteria were, come to receive maternal services in the study place and willing to participate in this study.

\subsubsection{Tool of the study}

A semi-structured questionnaire was prepared keeping in view the objectives and variables of the study. The Cronbach's alpha coefficient of original study was .82; these questionnaires were developed in English, and translated into local language by a bilingual expert. Part 1- Demographic Data Form (DDF) it is divided into 2 section Socio-demographic characteristics and pregnancy related characteristics consisting of 11 items, and Part 2- Dietary Behavior Questionnaire (DBQ) (Shom, Chunuan, and Chuntharapat, 2010). Dietary Behavior Questionnaire is a 4 points Likert scale ( $1=$ strongly disagree, $2=$ disagree, $3=$ agree, and $4=$ strongly agree) consisted of 21 items in 3 aspects: quality diet 11 items, supplementary diet 5 items, and avoiding diet 5 items. The higher number was indicated as higher dietary behavior.

\section{Results}

Table 1 illustrates that 135 pregnant women with anemia who participate in the study. The mean age of the sample was 25.41 years $(\mathrm{SD}=4.96)$. The Majority was Muslim $(91.9 \%)$. About $44.4 \%$ had an educational background of High school and $2.2 \%$ had no formal Education. There were 93.3\% housewives and $6.7 \%$ private employees. Among them $93.3 \%$ pregnant women living with their spouse and $6.7 \%$ were divorced or separated. There were $46.7 \%$ monthly incomes in between 11 to 20 thousand. Majority of them $(55.6 \%)$ continue Nuclear family and there living area $(73.3 \%)$ were in urban areas. More than half of them $(52.6 \%)$ were eating same time with their spouse. About $55.6 \%$ was multi gravid pregnant anemic women.

Table 1. Distribution of demographic characteristics of pregnant woman with anemia $(\mathrm{N}=135)$.

\begin{tabular}{|c|c|c|}
\hline Variables & $\mathbf{n}$ & $\%$ \\
\hline \multicolumn{3}{|c|}{ Age in years.' $(M=25.41, S D=4.96$, Min $=18, \operatorname{Max}=40)$} \\
\hline$\leq 19$ & 14 & 10.4 \\
\hline $20-24$ & 39 & 28.9 \\
\hline$\geq 25$ & 82 & 60.7 \\
\hline \multicolumn{3}{|l|}{ Religion } \\
\hline Muslim & 124 & 91.9 \\
\hline Hindu & 11 & 8.1 \\
\hline \multicolumn{3}{|l|}{ Educational status } \\
\hline No formal education & 3 & 2.2 \\
\hline Primary school & 43 & 31.9 \\
\hline Higher secondary & 60 & 44.4 \\
\hline College/university & 29 & 21.5 \\
\hline \multicolumn{3}{|l|}{ Occupation } \\
\hline Housewife & 126 & 93.3 \\
\hline Private employee & 9 & 6.7 \\
\hline \multicolumn{3}{|l|}{ Marital status } \\
\hline Married and living with spouse & 126 & 93.3 \\
\hline Divorced/separated & 9 & 6.7 \\
\hline \multicolumn{3}{|c|}{ Monthly Income(Thousands)* (M=21.05, SD=12.04, Min=5000,Max=70,000) } \\
\hline Less than 10000 & 28 & 20.7 \\
\hline 10001 to 20000 & 63 & 46.7 \\
\hline 20001 to 30000 & 29 & 21.5 \\
\hline More than 30000 & 15 & 11.1 \\
\hline
\end{tabular}




\begin{tabular}{lrr}
\hline Family characteristic & & \\
\hline Nuclear family & 74 & 55.6 \\
Extended family & 60 & 44.4 \\
\hline Place of living & 98 & 72.6 \\
\hline Urban area & 37 & 27.4 \\
Rural area & & \\
\hline Eating together at a time & 71 & 52.6 \\
\hline Yes & 65 & 47.4 \\
No & \multicolumn{3}{c}{} \\
\hline Gravida & 40 \\
Prime Gravida & 75 & 29.6 \\
Grand multi para & 55.6 \\
\hline
\end{tabular}

Table 2 shows that the distribution of Health status of pregnant women with anemia in Bangladesh. The pregnant anemic women's BMI was (50.4\%) over weight and $0.7 \%$ was under weight. The majority of them (88.8\%) had no disease before pregnancy in the last three months. Among the pregnant anemic mother $(3.0 \%)$ was suffering from heart disease. Among the respondent own perception there health status during pregnancy $(68.1 \%)$ is medium healthy, during pregnancy more than half $(58.4 \%)$ mother has increase their appetite and (17.8\%) feel same appetite as before. More than Half (71.9\%) pregnant anemic mother decreases sleeping time during their pregnancy. Among the respondent $67.4 \%$ pregnant women's hemoglobin concentration was 10.9 $\mathrm{g} / \mathrm{dl}$ and $32.6 \%$ pregnant woman was hemoglobin concentration $7-9.9 \mathrm{~g} / \mathrm{dl}$.

Table 2. Distribution of health status and dietary behavior of pregnant women $(n=135)$.

\begin{tabular}{|c|c|c|c|}
\hline Variables & Categories & n & $\%$ \\
\hline \multirow{30}{*}{$\begin{array}{l}\text { Health status related } \\
\text { characteristic }\end{array}$} & BMI $(M=25.79, \mathrm{SD}=3.25, \mathrm{Min}=18, \mathrm{Max}=37)$ & & \\
\hline & Under weight & 1 & 0.7 \\
\hline & Normal & 49 & 36.3 \\
\hline & Over weight & 68 & 50.4 \\
\hline & Obese & 17 & 12.6 \\
\hline & Disease & & \\
\hline & Nothing & 120 & 88.8 \\
\hline & Diabetic & 1 & 0.7 \\
\hline & HTN & 2 & 1.5 \\
\hline & Allergy & 2 & 1.5 \\
\hline & Heart Disease & 4 & 3.0 \\
\hline & Diabetes and Hypertension & 1 & 0.7 \\
\hline & Blood Pressure and Allergy & 2 & 1.5 \\
\hline & Others & 3 & 2.2 \\
\hline & Health status & & \\
\hline & Not Healthy & 4 & 3.0 \\
\hline & Little bit Healthy & 12 & 8.9 \\
\hline & Medium Healthy & 92 & 68.1 \\
\hline & Very Healthy & 27 & 20 \\
\hline & Appetite & & \\
\hline & Increase & 68 & 50.4 \\
\hline & Decrease & 43 & 31.9 \\
\hline & Same as before & 24 & 17.8 \\
\hline & Length of sleeping time & & \\
\hline & Increase & 68 & 50.4 \\
\hline & Decrease & 43 & 31.9 \\
\hline & Same as before & 24 & 17.8 \\
\hline & Hemoglobin & & \\
\hline & $7-9.9 \mathrm{~g} / \mathrm{dl}$ & 44 & 32.6 \\
\hline & $10-10.9 \mathrm{~g} / \mathrm{dl}$ & 91 & 67.4 \\
\hline \multirow[t]{4}{*}{ Dietary behavior } & & $\mathrm{M} \pm \mathrm{SD}$ & \\
\hline & Quality of diet & $27.39 \pm 4.39$ & \\
\hline & Supplementary diet & $12.59 \pm 2.39$ & \\
\hline & Avoiding diet & $16.20 \pm 2.33$ & \\
\hline
\end{tabular}


Table 3 shows descriptive statistics for each item in the dietary behaviour Quality of diet (11 items) M \pm SD $=27.39 \pm 4.39$. More than $50 \%$ pregnant anemic women agreed to take vegetables and fruits, snacks in between meal, extra food and iron containing diet and strongly agreed to avoid more sweet fatty food. More than $70 \%$ pregnant anemic women were agreed to take rice, fish or meat, multivitamins and water adequately. More than $90 \%$ respondent were agreed to take cook food. Among the respondent more than $60 \%$ respondent were disagreed to take vitamin A containing diet, egg, vegetable raw fruits olive oil, lemon amloky, plum guavas ,oily food and agreed to take tea coffee (67.4\%).

Table 3. Dietary behaviors of pregnant women with anemia in Bangladesh (Quality of diet (11 items).

\begin{tabular}{|c|c|c|c|c|c|}
\hline Variable & $\begin{array}{l}\text { Strongly } \\
\text { disagree } \\
\text { n }(\%)\end{array}$ & $\begin{array}{l}\text { Disagree } \\
\text { n }(\%)\end{array}$ & $\begin{array}{l}\text { Agree } \\
\text { n }(\%)\end{array}$ & $\begin{array}{l}\text { Strongly } \\
\text { agree } \\
\text { n (\%) }\end{array}$ & $\mathrm{M} \pm \mathrm{SD}$ \\
\hline $\begin{array}{l}\text { I eat balance diet including rice, fish, meat, } \\
\text { milk, vegetables and fruits each day. }\end{array}$ & $1(0.7)$ & $29(21.5)$ & $66(48.9)$ & $39(28.9)$ & $3.06 \pm 0.73$ \\
\hline I eat well cooked food. & $0(0)$ & $13(9.6)$ & $94(69.6)$ & $28(20.7)$ & $3.11 \pm 0.54$ \\
\hline I eat 1 egg every day. & $20(14.8)$ & $70(51.9)$ & $35(25.9)$ & $10(7.4)$ & $2.26 \pm 0.80$ \\
\hline I eat 3 meals per day. & $2(1.5)$ & $36(26.7)$ & $83(61.5)$ & $14(10.4)$ & $2.81 \pm 0.63$ \\
\hline $\begin{array}{l}\text { I eat } 2 \text { big spoons of vegetable and } 2 \text { pieces of } \\
\text { fruits per day. }\end{array}$ & $8(5.9)$ & $47(34.8)$ & $67(49.9)$ & $13(9.6)$ & $2.63 \pm 0.74$ \\
\hline I drink about eight glasses of water per day. & $2(1.5)$ & $33(24.4)$ & $88(65.2)$ & $12(8.9)$ & $2.81 \pm 0.60$ \\
\hline I eat snacks in between meals. & $5(3.7)$ & $58(43.0)$ & $60(44.4)$ & $12(8.9)$ & $2.59 \pm 0.70$ \\
\hline $\begin{array}{l}\text { I eat green leafy vegetables and raw fruits e.g., } \\
\text { olive, amloky, lemon, plum, guava etc. }\end{array}$ & $23(17.0)$ & $62(45.9)$ & $41(30.4)$ & $9(6.7)$ & $2.27 \pm 0.82$ \\
\hline I eat sea fish for good health. & $79(58.5)$ & $49(36.3)$ & $4(3.0)$ & $3(2.2)$ & $1.49 \pm 0.67$ \\
\hline I drink I glasses of milk per day. & $26(19.3)$ & $68(50.4)$ & $35(25.9)$ & $6(4.4)$ & $2.16 \pm 0.78$ \\
\hline I eat 1 table spoon of oil per day. & $22(16.3)$ & $84(62.3)$ & $23(17.0)$ & $6(4.4)$ & $2.10 \pm 0.71$ \\
\hline
\end{tabular}

Table 4 shows Supplementary diet ( 5 items) $\mathrm{M} \pm \mathrm{SD}=12.59 \pm 2.39$ and Avoiding diet $(5$ items) $\mathrm{M} \pm \mathrm{SD}=$ $16.20 \pm 2.33$. Among the respondent more than $66.7 \%$ respondent were disagreed to take Supplementary calcium rich diet e.g., milk, small fish each day and 48.9 agreed to take Supplementary balance diet including rice, fish, meat, milk, vegetables and fruits each day. More than $90 \%$ respondent disagrees to do not take milk, sea fish and disagree to take charcoaled foods and unclean food during their pregnancy.

Table 4. Dietary behaviors (Supplementary diet (5 items) and Avoiding diet (5 items)) of pregnant women with anemia in Bangladesh.

\begin{tabular}{|c|c|c|c|c|c|}
\hline Variable & $\begin{array}{l}\text { Strongly } \\
\text { disagree } \\
\text { n }(\%)\end{array}$ & $\begin{array}{l}\text { Disagree } \\
\mathrm{n}(\%)\end{array}$ & $\begin{array}{l}\text { Agree } \\
\text { n }(\%)\end{array}$ & $\begin{array}{l}\text { Strongly } \\
\text { agree } \\
\text { n }(\%)\end{array}$ & $\mathbf{M} \pm$ SD \\
\hline \multicolumn{6}{|l|}{ Supplementary diet (5 items) } \\
\hline $\begin{array}{l}\text { I take extra food that has iron e.g., green leafy } \\
\text { vegetables. }\end{array}$ & $6(4.4)$ & $28(20.7)$ & $87(64.4)$ & 14(10.4) & $2.81 \pm 0.67$ \\
\hline I take iron tablet each day. & $13(9.6)$ & $37(27.4)$ & $69(51.1)$ & $16(11.9)$ & $2.65 \pm 0.81$ \\
\hline I take multivitamin tablet each day. & $2(1.5)$ & $33(24.4)$ & $95(70.4)$ & $5(3.7)$ & $2.76 \pm 0.54$ \\
\hline $\begin{array}{l}\text { I take vitamin A containing diet e.g., yellow banana, } \\
\text { pumpkin, each day. }\end{array}$ & $29(21.5)$ & $56(41.5)$ & $39(28.9)$ & $11(8.1)$ & $2.26 \pm 0.89$ \\
\hline I take calcium rich diet e.g., milk, small fish each day. & $18(13.3)$ & $90(66.7)$ & $23(17.0)$ & $4(3.0)$ & $2.10 \pm 0.65$ \\
\hline \multicolumn{6}{|l|}{ Avoiding diet (5 items) } \\
\hline I don't take more sweet and fatty food. & 16(11.9) & $46(34.1)$ & $17(12.6)$ & $56(41.5)$ & $2.84 \pm 1.10$ \\
\hline I don't eat more salty diet. & $6(4.4)$ & $11(8.1)$ & $31(23.0)$ & $87(64.4)$ & $3.47 \pm 0.83$ \\
\hline I don't eat unclean and uncooked food. & $0(0$ & $1(.7)$ & $37(27.4)$ & $97(71.9)$ & $3.71 \pm 0.47$ \\
\hline I don't eat charcoaled foods (Burn wood, burn soil etc). & $3(2.2)$ & $0(0)$ & $22(16.3)$ & $110(81.5)$ & $3.77 \pm 0.56$ \\
\hline I don't take/drink tea/coffee in pregnancy & $24(17.8)$ & $67(49.6)$ & $9(6.7)$ & $35(25.9)$ & $2.41 \pm 1.06$ \\
\hline
\end{tabular}

Relationship between socio-demographic characteristic and Hemoglobin concentration of pregnant women in Table 5 showed that socio-demographic characteristic, Age $(\mathrm{F}=12.88, \mathrm{p}=.000)$, Level of education $(\mathrm{F}=2.92$, $\mathrm{p}=.036)$, Monthly income $(\mathrm{r}=0.19, \mathrm{p}=.027)$, Gravida $(\mathrm{F}=5.63, \mathrm{p}=.004)$ are significantly related with Hemoglobin concentration of pregnant women. 
Asian J. Med. Biol. Res. 2020, 6 (4)

Table 5. Relationship between socio-demographic characteristic and haemoglobin concentration (gm/dl) (anemia) of pregnant women.

\begin{tabular}{|c|c|c|c|}
\hline \multirow[t]{2}{*}{ Variables } & \multirow[t]{2}{*}{ Characteristic } & \multicolumn{2}{|c|}{ Hemoglobin concentration (g/dl) } \\
\hline & & $\mathbf{M} \pm$ SD & $\mathbf{t} / \mathbf{F} / \mathbf{r}(\mathbf{p})$ \\
\hline \multirow[t]{4}{*}{ Age } & & & $12.88(.000)$ \\
\hline & $\leq 19$ & $10.05 \pm 0.69$ & \\
\hline & $20-24$ & $9.22 \pm 1.13$ & \\
\hline & $\geq 25$ & $9.99 \pm 0.62$ & \\
\hline \multirow[t]{3}{*}{ Religion } & & & $-0.83(.408)$ \\
\hline & Muslim & $9.75 \pm 0.88$ & \\
\hline & Hindu & $9.98 \pm 0.75$ & \\
\hline \multirow[t]{5}{*}{ Level of $\mathbf{E}$} & & & $2.92(.036)$ \\
\hline & No formal education & $8.96 \pm 11.71$ & \\
\hline & Primary & $9.61 \pm 0.86$ & \\
\hline & Higher secondary & $9.95 \pm 0.77$ & \\
\hline & College and more & $10 \pm 0.82$ & \\
\hline \multirow[t]{3}{*}{ Occupatio } & & & $-0.53(.596)$ \\
\hline & Housewife & $9.76 \pm 0.87$ & \\
\hline & Service & $9.92 \pm 0.96$ & \\
\hline \multirow[t]{3}{*}{ Marital sta } & & & $2.14(.051)$ \\
\hline & Married and living with spouse & $9.86 \pm 0.73$ & \\
\hline & Divorce and separated & $9.0 \pm 1.48$ & \\
\hline \multirow[t]{5}{*}{ Monthly in } & & & $0.19(.027)$ \\
\hline & Less than 10000 & $9.61 \pm 0.85$ & \\
\hline & $10000-20000$ & $9.68 \pm 0.97$ & \\
\hline & $20001-30000$ & $9.91 \pm 0.70$ & \\
\hline & More than 30000 & $10.15 \pm 0.65$ & \\
\hline \multicolumn{2}{|c|}{ Family characteristic } & & $-0.30(.762)$ \\
\hline & Nuclear & $9.75 \pm 0.95$ & \\
\hline & Extended Family & $9.79 \pm 0.77$ & \\
\hline \multirow[t]{3}{*}{ Place of liv } & & & $1.01(.312)$ \\
\hline & Urban area & $9.81 \pm 0.83$ & \\
\hline & Rural Area & $9.64 \pm 0.97$ & \\
\hline \multicolumn{2}{|c|}{ Eating together with other family member } & & $1.26(.211)$ \\
\hline & Yes & $9.87 \pm 0.75$ & \\
\hline & No & $9.68 \pm 0.97$ & \\
\hline \multirow[t]{4}{*}{ Gestationa } & & & $1.15(.321)$ \\
\hline & $1^{\text {st }}$ trimester & $10.26 \pm 0.45$ & \\
\hline & $2^{\text {nd }}$ trimester & $9.72 \pm 0.94$ & \\
\hline & $3^{\text {rd }}$ trimester & $9.74 \pm 0.88$ & \\
\hline \multirow[t]{4}{*}{ Gravida } & & & $5.63(.004)$ \\
\hline & Prime gravid & $9.72 \pm 0.82$ & \\
\hline & Multi gravid & $9.94 \pm 0.67$ & \\
\hline & Grand multi Para & $9.24 \pm 1.33$ & \\
\hline
\end{tabular}

Note. $\mathrm{p}<0.05$

Relationship between health status, Dietary behavior and Hemoglobin concentration of pregnant women with anemia in Table 6 shows that Health condition of pregnant women according to their own perception has significantly related with hemoglobin concentration $(\mathrm{F}=10.89, \mathrm{p}=.000)$, and dietary behavior has significant positive relation with hemoglobin concentration $(\mathrm{r}=0.21, \mathrm{p}=.017)$. 
Table 6. Relationship between health status, dietary behavior and hemoglobin concentration of pregnant women with anemia.

\begin{tabular}{|c|c|c|c|}
\hline \multirow[t]{2}{*}{ Variable } & \multirow[t]{2}{*}{ Characteristic } & \multicolumn{2}{|c|}{ Hemoglobin concentration(g/dl) } \\
\hline & & $\mathbf{M} \pm \mathbf{S D}$ & $\mathbf{t} / \mathbf{F} / \mathbf{r}(\mathbf{P})$ \\
\hline \multirow[t]{21}{*}{ Health status } & Body mass Index & & $0.40(.750)$ \\
\hline & Under weight & $10.40 \pm 0.00$ & \\
\hline & Normal & $9.84 \pm 0.79$ & \\
\hline & Over weight & $9.70 \pm 0.99$ & \\
\hline & Obese & $9.81 \pm 0.62$ & \\
\hline & Disease before pregnancy & & $1.81(.081)$ \\
\hline & No disease & $9.74 \pm 0.90$ & \\
\hline & Yes disease & $10.02 \pm 0.52$ & \\
\hline & Health condition & & $10.89(.000)$ \\
\hline & Not healthy & $8.40 \pm 1.62$ & \\
\hline & Little bit healthy & $8.84 \pm 1.41$ & \\
\hline & Medium Healthy & $9.89 \pm 0.69$ & \\
\hline & Very Healthy & $9.96 \pm 0.54$ & \\
\hline & Appetite during pregnancy & & $0.93(.397)$ \\
\hline & Increase & $9.14 \pm 0.91$ & \\
\hline & Decrease & $9.81 \pm 0.86$ & \\
\hline & Same as before & $9.95 \pm 0.76$ & \\
\hline & Sleep during pregnancy & & $2.92(.057)$ \\
\hline & Increase & $9.62 \pm 0.96$ & \\
\hline & Decrease & $9.74 \pm 0.89$ & \\
\hline & Same as before & $10.18 \pm 0.31$ & \\
\hline \multirow{4}{*}{$\begin{array}{l}\text { Dietary } \\
\text { behavior }\end{array}$} & Quality of diet & $27.39 \pm 4.39$ & \\
\hline & Supplementary diet & $12.59 \pm 2.39$ & \\
\hline & Avoiding diet & $16.20 \pm 2.33$ & \\
\hline & Total dietary behavior & $56.03 \pm 6.15$ & $0.21(.017)$ \\
\hline
\end{tabular}

\section{Discussion}

This study focused on two part (1) Demographic pregnancy related characteristic and health status (2) Dietary behaviour are as follows. Socio demographic characteristics can play a major role in determining anaemia among pregnant woman. As regard socio-demographic characteristic of the studied among pregnant women with anaemia was found (Table 1) that majority of the participants were aged from $>25$ years, higher haemoglobin concentration group are below 19 Years (Table 4) and haemoglobin concentration is lower among the age group of 20-24 years (Table 4) that indicates low dietary habits than the other age group. This might be related to the effect of parity on increasing maternal age. This finding is consistent with a study done in Indian (Biswas and Baruah, 2014) reported that most of the anaemic pregnant women were in the age group 2024years.

Though the majorities' numbers of participant are Muslim (Table 1) shows in this study but Hindu religions haemoglobin concentration is slightly higher than Muslim religion (Table 4) anaemic women. In Bangladesh religious beliefs and customs influencing many aspect of women's eating habit. The woman of Muslim and Hindu group has some restricted food according to their religious view. In Muslim religion do not eat during day time in Ramadan. Religion is a very strong part of Bangladeshi culture and the corresponding food restriction can play added stress on woman during pregnancy. Restrictive dietary behaviours during pregnancy result in inadequate food intake both in quality and in quantity (Kedir et al., 2013).

Regarding family income anemia is likely to be more frequent among the families who had monthly income less10000 taka than other groups. Low income group has low hemoglobin concentration (more anemic). Similarly, studies in Ethiopia a reported that there is a relation between level of income and anemia, they found that low family income leads to food uncertainty and susceptible to malnutrition, one may assume the problem of iron deficiency anemia (Argaw et al., 2015). Poverty, ignorance, non-availability and/or failure to utilize available medical facilities have been shown to be associated with maternal anemia (Dayal and Dayal, 2014). Pregnant woman in Bangladesh are faced with limited access to a variety of foods which is most likely due to high level of poverty. In this study found that a higher number $(66.7 \%)$ of participants do not take egg daily may be due to low income. 
Gravidity and age of current pregnancy (trimester) were important variable. More than half $(55.6 \%)$ of the pregnant women were multi gravid. This has been shown significant association (Table 5) with hemoglobin concentration (anemia) in this study. The risk of developing anemia increases with the age of pregnancy (trimester). This study found that the risk of developing anemia was higher (Table 5) in third and second trimester when compared with those in the first trimester. This finding is consistent with a study done in Ethiopia that the prevalence of anemia was higher in pregnant women in the third and second trimesters (Alene and Dohe, 2014).

Dietary behavior was found to play major driving role in the incident of anemia among pregnant women. Study reported that only a few pregnant women consumed milk and eggs (Table 3). A study done in southwestern Bangladesh found similar result about milk and egg consumption and state that consumption of egg is essential during pregnancy and lactation as $t$ is one of the principle source of choline a vital diet component required for cell and brain development during pregnancy and early infancy (Shamim et al., 2016).

This study found that dietary behavior has significant positive relation with hemoglobin concentration $(\mathrm{r}=0.21$, $p=.017$ ). According to the WHO report, anemia in pregnant women generally assumed due to inadequate dietary iron intake in developing countries and similar finding was found by another study in Ethiopia that a strong significant association between anemia and not eating meat or organ meat (Argaw et al., 2015), and in Eastern Ethiopia found that Chewing chat and restrictive dietary habits that are associated with anemia (Kedir et al., 2013; Ejeta et al., 2014)

This study found that dietary behavior has significant positive relation with hemoglobin concentration. It is understood that pregnant women's dietary behaviors play an important role in the future health of her and infants. With an increased need during pregnancy pregnant women should improve their dietary practices. In this regards early dietary interventions might establish healthy dietary practices among pregnant women.

\section{Conclusions}

Dietary behaviour of pregnant woman with anaemia is influenced by a number of inter-related factors. This study found that increased age group, having no or only primary education, grand multi and primiparous women, and having not good health condition found less haemoglobin concentration indicated as less dietary intake. Their monthly income and dietary behaviour is positively influenced in the increasing of haemoglobin concentration. Nutritional anaemia in pregnancy is still a significant problem in Bangladesh. To reduce the prevalence, there is a need to improve the dietary level and strength health care seeking behaviour of women to ensure early diagnosis and management of nutritional deficiency anaemia and other medical conditions during pregnancy period.

\section{Conflict of interest}

None to declare.

\section{References}

Aikawa R, NC Khan, S Sasaki and CW Binns, 2006. Risk factors for Iron-deficiency anaemia among pregnant women living in rural Vietnam. Pub. Heal. Nutri., 9: 443-448.

Alene KA and AM Dohe, 2014. Prevalence of anemia and associated factors among pregnant women in an urban area of eastern Ethiopia. Anemia, 2014: 1-7.

Argaw B, A Argaw-Denboba, B Taye, A Worku and A Worku, 2015. Major risk factors predicting anemia development during pregnancy: Unmatched- Case Control Study. J. Comm. Med. Heal. Edu., 5: 2161-0711.

Bekele A, M Tilahun, and A Mekuria, 2016. Prevalence of anemia and its associated Factors among pregnant women attending antenatal care in health institutions of Arba Minch town, Gamo Gofa Zone, Ethiopia: A Cross-sectional study. Anemia, 2016:1073192

Biswas M and R Baruah, 2014. Maternal anaemia associated with socio-demographic factors among pregnant women of Boko-Bongaon Block Kamrup, Assam. Indian J. Bas. App. Med. Res., 3: 712-721.

Bondevik GT, B Eskeland, RJ Ulvik and M Ulstein, 2000. Anaemia in pregnancy: Possible causes and risk factors in Nepali women. European J. Clin. Nutri., 54: 3-8.

Campigotto AC, DCF Pinto, and FGF Albuquerque, 2015. Factors relating to iron deficiency anemia in pregnancy: an integrative review. Int. Arch. Med., 8:159.

Chowdhury HA, KR Ahmed, F Jebunessa, J Akter, S Hossain and M Shahjahan, 2015. Factors associated with maternal anaemia among pregnant women in Dhaka city. BMC women's Heal., 15: 77.

Christian P, KP West, SK Khatry, J Katz, SR Shrestha, EK Pradhan and RP Pokhrel, 1998. Night blindness of pregnancy in rural Nepal nutritional and health risks. Int. J. Epidemiol., 27: 231-237 
Ejeta E, B Alemnew, A Fikadu, M Fikadu, L Tesfaye, T Birhanu and E Nekemte, 2014. Prevalence of anaemia in pregnant womens and associated risk factors in Western Ethiopia. Food Sci. Qual. Man., 31: 82-91.

Haider BA, I Olofin, M Wang, D Spiegelman, M Ezzati and WW Fawzi, 2013. Anaemia, prenatal iron use, and risk of adverse pregnancy outcomes: Systematic review and meta-analysis. British Med. J., 346: 1-19.

Hoque M, E Hoque and SB Kader, 2009. Risk factors for anaemia in pregnancy in rural KwaZulu-Natal, South Africa: Implication for health education and health promotion. South African Fam. Prac., 51: 68-72.

Imdad A and ZA Bhutta 2012. Routine iron/folate supplementation during pregnancy: Effect on maternal anaemia and birth outcomes. Paedia. Perin. Epidemiol., 26:168-177.

Islam MN and MO Cliah, 2005. Knowledge and attitude of urban pregnant women of Bangladesh toward nutrition, health care practice and delivery place. J. Med. Sci., 5: 116-119.

Dayal S and A Dayal, 2014. Prevalence and consequences of anaemia in pregnancy. Int. J. Med. Res. Rev., 2: 296-299.

Kedir H, Y Berhane and A Worku, 2013. Khat chewing and restrictive dietary behaviors are associated with anemia among pregnant women in high prevalence rural communities in eastern Ethiopia. Plos One, 8: e78601.

Northstone K, P Emmett and I Roger, 2008. Dietary patterns in pregnancy and associations with socio demographic and lifestyle factors. Eur. J. Clin. Nutr., 62: 471-479

Shamim AA, SR Mashreky, T Ferdous, K Tegenfeldt, S Roy, AF Rahman and SR Siddiquee, 2016. Pregnant women diet quality and its sociodemographic determinants in Southwestern Bangladesh. Food Nutri. Bull., 37: 14-26.

Shom ER, 2010. Perceived nutritional status, perceived dietary self-efficacy, and dietary behavior among Bangladeshi pregnant women. Master Thesis, Department of Nursing Science, Prince of Songkla University, Thailand, pp. 116. 